

D. N. Mathur

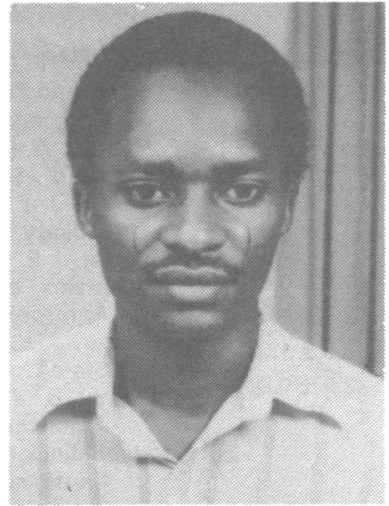

A. L. Toriola

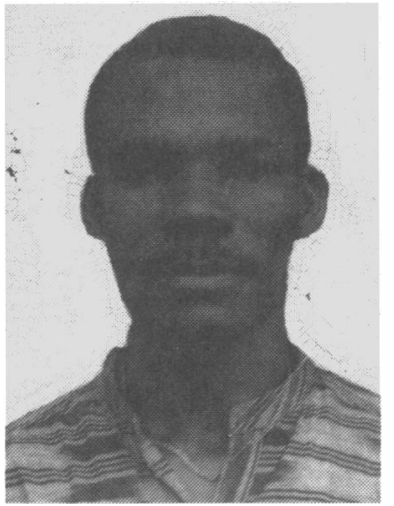

N. U. Igbokwe

\title{
SOMATOTYPES OF NIGERIAN ATHLETES OF SEVERAL SPORTS
}

\author{
D. N. MATHUR, MD*, A. L. TORIOLA, MA and N. U. IGBOKWE, MA \\ Institute of Physical Education, University of Ife, Nigeria
} \begin{abstract}
ectomesomorphs.
INTRODUCTION

Somatotype has been used to demonstrate similarities and differences between several groups of individuals including athletes of different sports. Since 1967, the Heath-Carter somatotype method has been utilised successfully by several investigators (Carter, 1970; Hebbelinck et al, 1973; Carter and Parizkova, 1978). Mostly, studies on somatotyping have been carried out on athletes of European and North American countries (Parnell, 1958; Åstrand et al, 1963; Heath and Carter, 1967; Houston and Green, 1976; Ross et al, 1977; Kidd and Winter, 1983). Data are lacking, however, on somatotype studies of Nigerian athletes. Consequently, the purpose of the present investigation was to assess the somatotype characteristics of elite male athletes of some popular sports in Nigeria.
\end{abstract}

ABSTRACT

Somatotype ratings and percentage body fat of 131 elite Nigerian male athletes, average 24.2 years of age, and belonging to badminton $(n=18)$, basketball $(n=30)$, field hockey $(n=24)$, handball $(n=16)$, judo $(n=18)$, and soccer $(n=25)$ teams were determined. Basketball, handball and soccer players were taller and heavier, and had low percent fat values as compared with the other athletic groups. Judokas and hockey players were endomesomorphs. Other sports groups were predominantly

\section{METHODS}

\section{Subjects}

A total of 131 elite male athletes who were between the ages of 18.6 and 26.9 years, and belonging to badminton, basketball, field hockey, handball, judo and soccer teams acted as subjects of this study.

\section{Protocol}

Measurements were taken during the peak of the competition season. Anthropometric measurements needed to calculate the subjects' somatotype ratings and percent body fat were made according to the technique described by Behnke and Wilmore (1974). These measurements were height, weight, triceps, subscapular, suprailiac, thigh and calf skinfolds, bi-epicondylar diameter of femur and

\section{*Present address}

Netaji Subhas National Institute of Sport,

Motibagh,

PATIALA

Punjab,

147001 India humerus, and flexed biceps and calf girths. All skinfold measurements were taken on the right side of the body with the Harpenden skinfold caliper. Subjects' somatotypes were determined by using the Heath-Carter anthropometric method (Carter, 1980). Percent body fat was estimated using the nomogram developed by Sloan and Weir (1970).

\section{Statistical analysis}

Means and standard deviations for each somatotype component and percent body fat for the athletic groups were computed.

\section{RESULTS AND DISCUSSION}

The height and weight of basketball, handball and soccer groups were noted to be higher than those of badminton, hockey and judo groups (Table I).

TABLE I

\begin{tabular}{lccccr}
\hline Category & $\mathrm{n}$ & $\begin{array}{c}\text { Age } \\
(\mathrm{yr})\end{array}$ & $\begin{array}{c}\mathrm{Ht} \\
(\mathrm{cm})\end{array}$ & \multicolumn{1}{c}{$\begin{array}{l}\mathrm{Wt} \\
(\mathrm{kg})\end{array}$} & \% Fat \\
\hline Badminton & 18 & $22.3 \pm 2.4$ & $172.4 \pm 5.3$ & $67.9 \pm 3.6$ & $8.2 \pm 1.7$ \\
Basketball & 30 & $24.8 \pm 2.6$ & $182.5 \pm 6.8$ & $76.4 \pm 4.9$ & $7.6 \pm 1.8$ \\
Handball & 16 & $21.4 \pm 2.7$ & $180.4 \pm 4.8$ & $75.2 \pm 4.7$ & $7.8 \pm 1.2$ \\
Hockey & 24 & $24.3 \pm 4.6$ & $170.2 \pm 3.8$ & $68.2 \pm 5.2$ & $10.5 \pm 1.5$ \\
Judo & 18 & $22.4 \pm 3.8$ & $170.3 \pm 4.4$ & $67.4 \pm 3.8$ & $12.2 \pm 1.6$ \\
Soccer & 25 & $25.2 \pm 4.8$ & $175.1 \pm 5.1$ & $72.9 \pm 6.4$ & $9.3 \pm 1.5$ \\
\hline
\end{tabular}

As shown in Table II, judokas and hockey players were unique categories of athlete. They had higher percent fat values and were endomesomorphs. Athletes of all other sport groups were ectomesomorphs (Fig. 1). In addition, basketball and handball players had least percent fat values. This supports the ectomesomorphic characteristics of basketball and handball players.
Physical characteristics of Nigerian Athletes (Mean \pm SD) 
TABLE II

Somatotype characteristics of Nigerian Athletes (Mean \pm SD)

$\begin{array}{lccc}\text { Category } & \text { Endomorphy } & \begin{array}{c}\text { Somatotype } \\ \text { Mesomorphy }\end{array} & \text { Ectomorphy } \\ \text { Badminton } & 2.2 \pm 0.9 & 3.9 \pm 1.1 & 2.9 \pm 0.6 \\ \text { Basketball } & 1.9 \pm 0.5 & 5.3 \pm 1.7 & 3.4 \pm 1.1 \\ \text { Handball } & 1.9 \pm 0.8 & 4.9 \pm 1.8 & 3.2 \pm 0.8 \\ \text { Hockey } & 2.9 \pm 0.7 & 4.8 \pm 2.1 & 2.7 \pm 1.4 \\ \text { Judo } & 3.6 \pm 1.1 & 5.1 \pm 1.1 & 2.6 \pm 1.0 \\ \text { Soccer } & 2.2 \pm 0.8 & 5.4 \pm 1.5 & 2.9 \pm 0.9\end{array}$

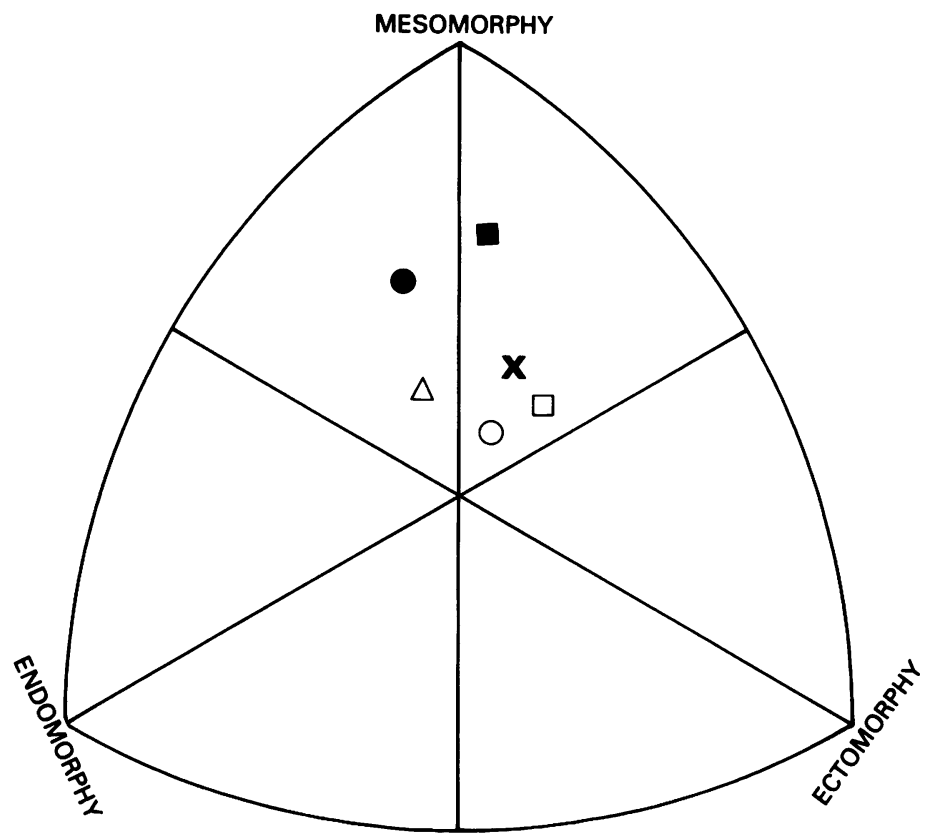

Fig. 1: Mean somatotype distributions of Nigerian athletes: $\square$ badminton players $(n=18)$; $O$ basketball players $(n=30) ; X$ handball players $(n=16)$; $\triangle$ hockey players $(n=24)$; judokas $(n=18)$; soccer players $(n=25)$.

\section{References}

Astrand, P. O., Engstrom, L., Eriksson, B. O., Karlberg, P., Nylander, I., Saltin, B. and Thoren, C., 1963 "Girl swimmers". Acta Paedriatica Scandinavica, Supplement, 147.

Behnke, A. R. and Wilmore, J. H., 1974 "Evaluation and regulation of body build". Englewood Cliffs. New Jersey: Prentice Hall pp. 38-50.

Carter, J. E. L., 1970 "The somatotypes of athletes - a review". Human Biology 42: 535-569.

Carter, J. E. L. and Parizkova, J., 1978 "Changes in somatotypes of European males between 17 and 24 years". American Journal of Physical Anthropology 48: 251-254.

Carter, J. E. L., 1980 "The Heath-Carter somatotype method". San Diego: State University Syllabus Service, pp. 2-5, 5-5.

Heath, B. and Carter, J. E. L., 1967 "A modified somatotype method". American Journal of Physical Anthropology 27:57-74.

Hebbelinck, M., Duquet, W. and Ross, W. 1973 "A practical outline for HeathCarter somatotyping method applied to children". In: Pediatric Work Physiology Proceedings, 4th International Symposium. Wingate Institute, Israel, pp. 71-84.

Houston, M. E. and Green, H. J., 1976 "Physiological and anthropometric characteristics of elite Canadian ice hockey players". Journal of Sports Medicine and Physical Fitness 16: 123-128.

Kidd, D. and Winter, E. M., 1983 "Some anthropometric characteristics of the national junior hammer squad". British Journal of Sports Medicine 17: 152-153.

Parnell, R . W., 1958 "Behaviour and physique". Edward Arnold: London.

Ross, W. D., Brown, S. R., Yu, J. W. and Faulkner, R. A., 1977 "Somatotype of Canadian figure skaters". Journal of Sports Medicine and and Physical Fitness 17: 195-205.

Sloan, A. and Weir, J., 1970 "Nomograms for prediction of body density and total body fat from skinfold measurements". Journal of Applied Physiology 28: 221-222.

Title:

Editors: $\quad$ L. J. Krakauer, J. L. Anderson, F. George, R. J. Shephard and J. S. Torg

Publishers: $\quad$ Year Book Medical Publishers Inc., Chicago. UK Agents - Blackwell Scientific Publications, Oxford ISBN 0-8151-5166-6. ISSN 0162-0908

Price: $£ 43 \quad 459$ pages Hard cover Indices - Subject and Author

Black and white figs. and graphs

Literature reviewed up to February 1985 is reviewed, most of the reviews taking up approximately one page, and many with graphs, photographs or X-Rays, and often followed by comments from the editors. The book opens with a leading article, 'The Exercise Hypothesis', by E. R. Eichner, the haematologist from Oklahoma University, and reviews current theories on factors predisposing to coronary artery disease, the benefits and dangers of exercise and sensible precautions that can be taken. The main part of the book is subdivided into seven sections - exercise physiology, general medicine, biomechanics, sports injury, paediatric sports medicine, women in sport and athletic training.

As in previous editions, the great majority of papers abstracted are from the USA, but there is an increased number from Europe, Australia, South Africa and elsewhere, which is welcome. Eight papers from Brit.Jnl.Sports Med. are abstracted (though several were among our many contributions from the USA). The job of making abstracts from 99 separate Journals, some like Lancet and BMJ published weekly, must be enormous, and I would regard this book as a most useful annual abstract for the research library, either in the Clinical Sciences or Sports Sciences collections. 